Jurnal Quantum Teknika

Vol. 1, No. 1, Hal 1-9, Oktober 2019

\title{
Studi Eksperimental Pengaruh Perbedaan Sudut Kemiringan terhadap Temperatur Onset Termoakustik Generator Gelombang Berdiri
}

\author{
Rinasa Agistya Anugrah* \\ Program Studi Teknik Mesin Universitas Muhammadiyah Yogyakarta, \\ Jl. Brawijaya, Tamantirto, Kasihan, Bantul, Daerah Istimewa Yogyakarta, Indonesia \\ Penulis korespondensi: rinasaanugrah@umy.ac.id
}

Histori artikel: diserahkan 05 April 2019, direviu 22 Juni 2019, direvisi 04 Juli 2019

\begin{abstract}
Thermoacoustic generator ia one of energy conversion device that change thermal energy to acoustic form energy. This device can get many beneficial of thermal energy which banned and not be used again from industry, devices of the hospitals, geothermal, and solar energy. The device consist or two type, standing wave and traveling wave. In the research used a standing wave thermoacoustic generator because of the cost is relatively cheaper and the construction is easy to set than traveling wave type. Onset temperature is one of the most important parameter in thermoacoustic generator to be researched. In that aplication, onset temperature can representated how many the performance of this device, if seen by input energy used the system of the thermoacustic generator. Decreasing onset temperature could make decrease of thermal energy used to generator. Beside stack and resonator length, the other parameter that more important to research is tilted angles. In this researched would be done researched with variation of tilted angles $-90^{\circ}, 0^{\circ}$, dan $90^{\circ}$. It would be found the effective tilted angle used, the performance was presented by the least onset temperature. The result was the tilted angle decreased when the onset temperature decreased too. If seen by the input energy, the best performance of thermoacoustic generator is on $90^{\circ}$ tilted angle.

Keywords: Thermoacoustic generator, standing wave, tilted angle, onset temperatur
\end{abstract}

DOI: $10.18196 /$ jqt.010101

Web: http://journal.umy.ac.id/index.php/qt

\section{PENDAHULUAN}

Beberapa tahun yang lalu, topik mengenai lingkungan adalah topik yang menarik bagi semua peneliti dan insinyur di dunia. Mereka menciptakan teknologi yang mempermudah kehidupan manusia, namun beberapa teknologi tersebut ada yang dapat merusak lingkungan. Mesin motor bakar dan refrigerator adalah teknologi di abad ke 20 yang berkaitan erat dengan topik lingkungan tersebut. Mesin tersebut memiliki emisi gas buang yang berbahaya bagi lingkungan dan menghasilkan limbah panas yang terbuang ke lingkungan. Emisi gas buang dan gas rumah kaca $\left(\mathrm{CO}_{2}\right.$, Chlorofluorocarbons, $\mathrm{CO}$, dan lain-lain) adalah limbah dari teknologi tersebut yang dapat menyebabkan lapisan ozon rusak. Lapisan ozon atmosfer berfungsi untuk menyerap radiasi sinar matahari yang berbahaya untuk kehidupan di bumi. Selain itu limbah panas yang terbuang ke lingkungan tidak dimanfaatkan menjadi energi baru lagi yang bisa dipakai. Beberapa tahun yang lalu peneliti telah bekerja untuk membuat penemuan teknologi yang dapat meminimalisasi dampak lingkungan dengan memanfaatkan potensi panas yang masih dimiliki limbah. Salah satu teknologi yang mampu memberi solusi dari permasalahan tersebut adalah mesin yang bekerja dengan konsep termoakustik.

Termoakustik adalah suatu bidang yang mempelajari fenomena fisis yang melibatkan perbedaan temperatur dapat membangkitkan gelombang akustik, atau sebaliknya, gelombang akustik dapat menimbulkan perbedaan temperatur. Termoakustik menjelaskan tentang 
konversi energi yang terjadi pada interaksi osilasi temperatur yang diikuti osilasi tekanan dalam gelombang akustik dengan dinding batas. Untuk pengaplikasian fenomena ini dibutuhkan suatu alat yang disebut dengan mesin termoakustik. Mesin termoakustik dibagi menjadi dua macam. Mesin yang mampu menghasilkan gelombang akustik akibat adanya perbedaan temperatur disebut termoakustik generator (thermoacoustic engine atau thermoacoustic generator atau thermoacoustic prime mover). Kemudian mesin yang mampu menghasilkan perbedaan temperatur akibat adanya kerja dari gelombang akustik. Apabila produksi temperatur dingin disebut pendingin termoakustik (thermoacoustic refrigerator) dan jika produksi temperatur panas disebut pompa kalor termoakustik (thermoacoustic heat pump). Adapun beberapa keunggulannya adalah memiliki reliabilitas tinggi, relatif murah, ramah lingkungan, no moving part, dan terintegrasi (Setiawan, 2005).

Termoakustik generator merupakan alat untuk mengkonversi kalor menjadi gelombang akustik yang menggunakan aliran kalor antara sisi panas dan sisi dingin untuk menghasilkan gelombang bunyi. Gelombang akustik yang dihasilkan termoakustik generator ada dua tipe, yaitu gelombang berdiri (standing wave) dan gelombang berjalan (traveling wave). Kedua tipe gelombang ini bergantung pada jenis resonator yang digunakan. Termoakustik generator membutuhkan gradien temperatur yang tinggi untuk menghasilkan bunyi. Gradien temperatur sendiri terjadi di bagian yang sering disebut "stack" (untuk mesin termoakustik gelombang berjalan disebut regenerator), diletakkan antara sisi panas dan sisi dingin dari termoakustik generator.

Termoakustik generator dapat diaplikasikan pada dunia otomotif yaitu pada kendaraan bermotor khususnya. Telah dilakukan penelitian yang mengarah pada perkembangan otomotif di dunia. Hatazawa dkk. (2004) meneliti tentang driven pendingin termoakustik dengan memanfaatkan panas dari gas buang mesin kendaraan bermotor. Zoontjens (2005) melakukan penelitian yang sama dengan Hatazawa namun pendingin termoakustik yang dihasilkan, digunakan sebagai pengganti pendingin udara konvensional pada kendaraan bermotor.
Penelitian pada stack ini telah dilakukan oleh peneliti sebelumnya. Murti (2015) melakukan penelitian meningkatkan efisiensi termoakustik generator jenis gelombang berdiri dengan mengoptimasi stack dari sisi ukuran, bentuk, material, dan harga. Stack yang digunakan adalah stack wire mesh screen stainless steel (kasa berbahan stainless steel).

Parameter lain yang juga penting adalah panjang resonator. Hariharan dkk. (2012) melakukan penelitian dengan variasi geometri stack dan panjang resonator untuk mengetahui performa termoakustik generator gelombang berdiri. Pada penelitian ini variasi panjang resonator yang dilakukan dengan panjang 200, 300, 400, dan $500 \mathrm{~mm}$.

Selain stack dan panjang resonator ada parameter lain yang tidak kalah penting yaitu penempatan posisi sudut kemiringan pada termoakustik generator gelombang berdiri. Yaitu dengan memvariasikan penempatan posisi pada alat termoakustik generator dengan berbagai sudut kemiringan. He dkk. (2013) melakukan penelitian menggunakan gas kerja Nitrogen $\left(\mathrm{N}_{2}\right)$ pada tekanan 0,34 Mpa dengan variasi perbedaan sudut kemiringan dengan interval $-90^{\circ}$ sampai $90^{\circ}$, posisi horizontal $\left(0^{\circ}\right)$, kemiringan $-45^{\circ}$ dan $45^{\circ}$, serta vertikal $-90^{\circ}$ dan $90^{\circ}$. Penempatan posisi sudut kemiringan inilah diteliti tentang konveksi natural yang terjadi pada stack. Variasi sudut kemiringan tersebut mempengaruhi konveksi natural yang terjadi sehingga mempengaruhi pula temperatur onset pada termoakustik generator. Oleh karena itu, penulis ingin meneliti juga pengaruh perbedaan sudut kemiringan pada termoakustik generator, namun dengan gas kerja lain yaitu udara pada tekanan 1 atm dan pada temperatur kamar $\left(25^{\circ} \mathrm{C}\right)$. Dalam hal ini ingin diketahui apakah udara tersebut memiliki karakteristik yang sama dalam pengaruhnya pada temperatur onset termoakustik generator.

\section{TINJAUAN PUSTAKA}

Shen dkk. (2009) melakukan penelitian untuk mengetahui performa termodinamika pada Thermoacoustic Engine dengan perbedaan fluida kerja pada perbedaan sudut kemiringan penempatan engine dengan range $-90^{\circ}$ sampai $90^{\circ}$ dengan interval angular $45^{\circ}$. Hasil dari pengaruh perbedaan sudut kemiringan terhadap temperatur onset berdasarkan viscidity fluida 
kerjanya. Penelitian ini menggunakan fluida kerja Nitrogen $\left(\mathrm{N}_{2}\right)$, Helium (He), campuran Nitrogen-Helium (He-Ne mixture) dengan berbagai variasi perbandingan campurannya, Argon (Ar), dan campuran Helium-Argon (HeAr mixture).

He dkk. (2013) melakukan penelitian untuk menganalisis termodinamika pada proses onset, penjelasan baru mengenai onset dan damping behavior, dan hasil eksperimental pada perbedaan sudut kemiringan penempatan alat.
Power engine termoakustik yang digunakan adalah dengan pemanas elektrik. Sensor temperatur dipasang 7 titik mulai dari HHX (Hot Heat Exchanger) pada T1 sampai CHX (Cold Heat Exchanger) pada T7 ditunjukkan Gambar 1. Tujuannya untuk mengetahui distribusi temperatur pada stack disetiap titik sepanjang sumbu-x mulai dari HHX sampai CHX. Sensor Tekanan dipasang 7 titik, 6 pada resonator tube dan 1 pada resonance cavity untuk mengetahui tekanan disetiap titiknya.

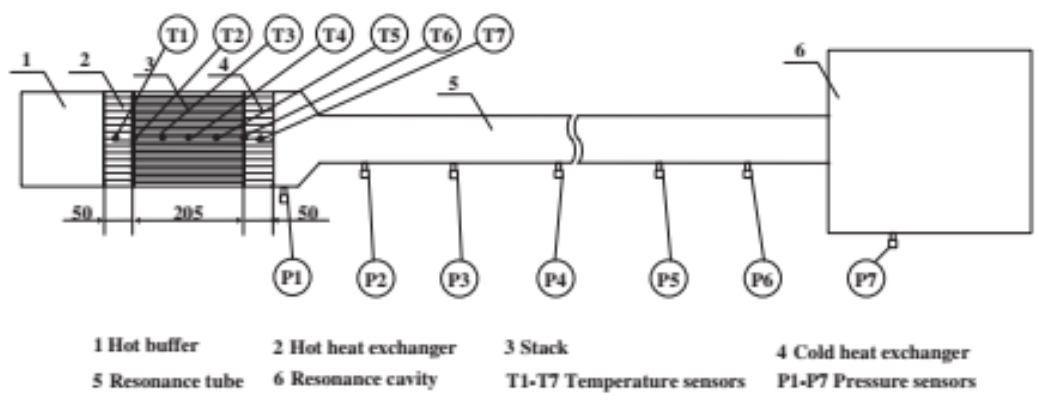

GAMBAR 1. Skema termoakustik generator gelombang berdiri (He dkk. 2013)

Pan dkk. (2014) melakukan penelitian yang sama hanya saja perbedaannya pada power engine yang digunakan adalah pemanas elektrik namun mentransferkan panasnya ke stack tube dengan radiasi kemudian secara konduksi menuju HHX. Osilasi akustik dalam resonator dilengkapi dengan loudspeaker serta distribusi kecepatan dalam stack dan temperatur diukur.

TABEL 1. Perkembangan penelitian sebelumnya pada termoakustik generator dengan sudut kemiringan

\begin{tabular}{|c|c|c|c|c|}
\hline No. & Nama Penulis & Geometri & $\begin{array}{l}\text { Variasi Sudut } \\
\text { Kemiringan }\end{array}$ & Gas Kerja \\
\hline 1 & Shen dkk. (2009) & $\begin{array}{l}\text { Diameter HHX, } \\
\text { Stack, CHX, dan } \\
\text { Resonator : 48, 54, } \\
\text { 48, dan } 36 \mathrm{~mm} . \\
\text { Panjang HHX, Stack, } \\
\text { CHX, dan Resonator : } \\
\text { 50, 205, 50, dan } 1500 \\
\text { mm. }\end{array}$ & $\begin{array}{l}-90^{\circ},-45^{\circ}, 0^{\circ} \\
45^{\circ}, \text { dan } 90^{\circ} .\end{array}$ & $\begin{array}{l}\text { Nitrogen }\left(\mathrm{N}_{2}\right) \text {, Helium }(\mathrm{He}) \text {, } \\
\text { campuran Nitrogen-Helium } \\
\text { (He-Ne mixture) dengan } \\
\text { berbagai variasi } \\
\text { perbandingan campurannya, } \\
\text { Argon (Ar), dan campuran } \\
\text { Helium-Argon (He-Ar } \\
\text { mixture). }\end{array}$ \\
\hline 2 & He dkk. (2013) & - & $\begin{array}{l}-90^{\circ},-45^{\circ}, 0^{\circ}, \\
45^{\circ}, \text { dan } 90^{\circ} .\end{array}$ & $\begin{array}{l}\text { Nitrogen }\left(\mathrm{N}_{2}\right) \text { pada tekanan } \\
0,34 \mathrm{MPa}\end{array}$ \\
\hline 3 & Pan dkk. (2014) & - & $\begin{array}{l}-90^{\circ},-45^{\circ}, 0^{\circ}, \\
45^{\circ}, \text { dan } 90^{\circ} .\end{array}$ & ( \\
\hline
\end{tabular}




\section{LANDASAN TEOR}

Gambar 2 adalah skema termoakustik generator yang terdiri dari stack yang disisipkan diantara HHX (hot heat exchanger) dan CHX (cold heat exchanger). Komponen ini diletakkan di dalam resonator dengan kedua sisi tertutup. Termoakustik generator menyerap kalor $\left(Q_{h}\right)$ dari sumber kalor bertemperatur tinggi $\left(T_{h}\right)$ dan menghasilkan kerja $(W)$ dengan membuang kalor $\left(Q_{c}\right)$ ke lingkungan yang bersuhu rendah $\left(T_{c}\right)$ melalui CHX. Ketika kalor $\left(Q_{h}\right)$ masuk ke HHX, sisi stack yang terdekat dengan HHX akan memiliki temperature tinggi sehingga terjadi gradien temperatur pada kedua sisi stack karena sisi stack yang berdekatan dengan CHX tidak mengalami perubahan temperatur. Ketika gradien temperatur stack mencapai titik minimum atau kritis maka secara spontan terjadi osilasi akustik atau timbul bunyi.
Siklus termoakustik diilustrasikan oleh Gambar 3 bagian stack yang memiliki temperatur tinggi (berwarna merah) dan bertekanan rendah menyebabkan gas kerja bergerak ke kiri dan terkompresi karena membuang kalor $(d q)$ ke dinding stack (1). Gas kerja yang terkompresi ini sekarang memiliki temperatur lebih rendah daripada dinding stack di dekatnya sehingga dinding melepaskan kalor $(d q)$ ke gas kerja sehingga gas kerja mengalami ekspansi termal dan volumenya membesar (2). Kemudian, gas kerja yang berekspansi kembali ke kanan yang membuat tekanan sisi kanan menjadi turun (3). Gas kerja memiliki temperatur lebih tinggi daripada dinding stack di dekatnya, sehingga gas kerja memberikan kalor ke dinding stack dan gas kerja kembali terkompresi (4). Siklus ini terus berulang dan efeknya adalah terjadi osilasi akustik gas kerja dan gelombang bunyi timbul saat gas kerja berekspansi karena menyerap kalor dari dinding stack.

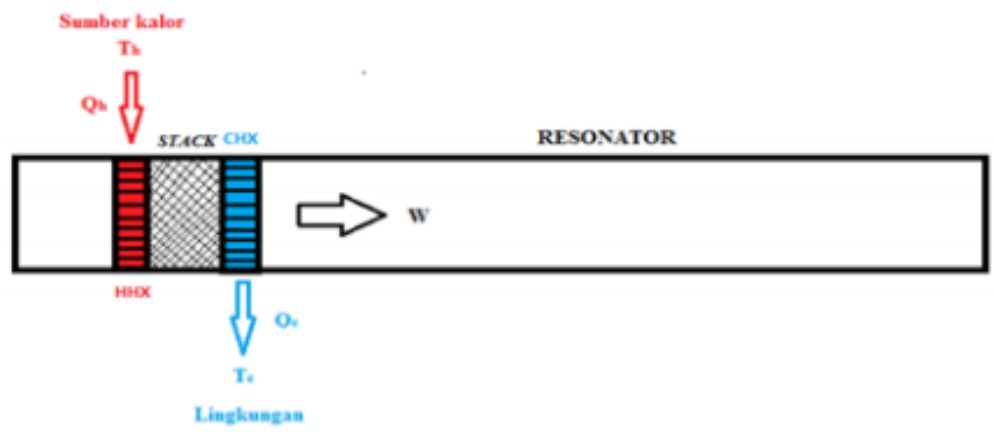

GAMBAR 2. Skema konsep termoakustik generator gelombang berdiri (Murti, 2015)

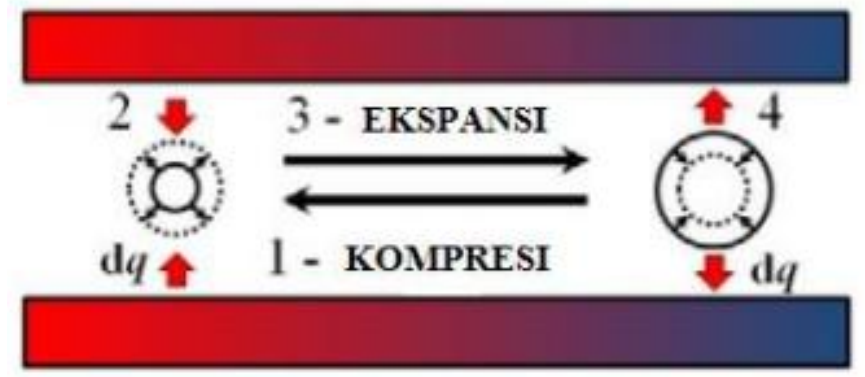

GAMBAR 3. Proses terjadinya osilasi akustik di dalam stack (Murti, 2015)

\section{Kondisi Temperatur Kritis dan Onset}

Osilasi ini tidak akan terjadi apabila perbedaan temperatur antar sisi stack tidak mencapai atau melebihi temperatur kritis. Hal ini juga disebut temperatur onset, dituliskan dalam persamaan (Arafa, 2011):

$$
\Delta T_{k r i t i s}=\frac{P \omega}{\rho c_{p} u}
$$

dimana $\mathrm{P}$ adalah tekanan dinamik, $\omega$ adalah frekuensi angular, $\mathrm{u}$ adalah kecepatan osilasi gas kerja, $\rho$ adalah kerapatan gas, dan $c_{p}$ adalah kalor spesifik per satuan massa gas. Ketika gas 
kerja sudah berosilasi karena beda temperatur pada kedua sisi stack. $\Delta T_{\text {kritis }}$ adalah beda temperatur pada sisi stack ketika daya akustik dari stack sama dengan nol $\left(\dot{W}_{\text {stk }}=0\right)$. Daya akustik pada thermoacoustic engine berasal dari resonator, stack, dan dua buah heat exchanger seperti pada persamaan berikut:

$\dot{W}=\dot{W}_{s t k}+\dot{W}_{H E}+\dot{W}_{\text {res }}$

$\mathrm{W}_{\mathrm{HE}}$ dan $\mathrm{W}_{\text {res }}$ adalah disipasi (bernilai negatif) pada heat exchanger dan resonator. Nilai $\mathrm{W}_{\text {stk }}$ bisa negatif atau positif tergantung dari beda temperatur dan posisi stack. Pada saat beda temperatur kritis $\Delta T_{\text {kritis }}$ nilai $\mathrm{W}$ negatif namun seiring bertambahnya beda temperatur, nilai $\mathrm{W}_{\text {stk }}$ menjadi positif sehingga $\mathrm{W}$ pun ikut bernilai positif. Pada beda temperatur ini dinamakan beda temperatur onset $\Delta T_{\text {onset }}$. Oleh karena itu nilai beda temperatur kritis $\Delta T_{\text {kritis }}$ akan selalu lebih rendah dibandingkan dengan beda temperatur onset $\Delta T_{\text {onset }}$ (Setiawan, 2013).

\section{METODE PENELITIAN}

Peralatan utama yang digunakan dalam penelitian ini meliputi pipa resonator, heat exchanger, termokopel tipe-K, pemanas listrik, dan pompa air. Peralatan tersebut harus dalam keadaan yang baik saat akan dilakukan set up penelitian.

Pipa resonator berbahan stainless steel 304 dan berdiameter dalam 2 inchi $(52,5 \mathrm{~mm} /$ sesuai ukuran spesifikasi diameter dalam pipa) dan dengan tebal pipa 3,92 mm digunakan sebagai tempat untuk gas kerja, stack, dan dua buah heat exchanger. Terdapat satu bagian pipa yang dihubungkan dengan flange. Pipa tersebut memiliki panjang $390 \mathrm{~mm}$.

Heat exchanger merupakan salah satu komponen thermoacoustic engine. Heat exchanger berfungsi sebagai alat untuk memasukkan dan melepaskan kalor ke dalam sistem agar terjadi perbedaan temperatur di kedua sisi stack sehingga efek termoakustik dapat terjadi. Bahan heat exchanger harus memiliki konduktivitas termal yang baik agar perpindahan kalor dapat terjadi secara optimal. Kedua heat exchanger (hot heat exchanger dan cold heat exchanger) pada penelitian ini terbuat dari tembaga. Hot heat exchanger (HHX) berdiameter 52,5 $\mathrm{mm}$, panjang $40 \mathrm{~mm}$, memiliki dua ukuran pori-pori yaitu berdiameter $3 \mathrm{~mm}$ dan $5 \mathrm{~mm}$. Cold heat exchanger (CHX) berdiameter 52,5 mm, panjang $40 \mathrm{~mm}$, dan memiliki pori-pori berdiameter $3 \mathrm{~mm}$. Agar temperatur CHX stabil, maka bagian luar pipa resonator yang berhimpitan dengan CHX diberi sirkulasi air.

Termokopel tipe-K digunakan untuk mengetahui temperatur di dalam sistem karena memiliki range temperatur besar. Terdapat tiga termokopel dalam penelitian ini. Dua termokopel digunakan untuk mengukur temperatur di kedua sisi stack. Termokopel yang lain digunakan untuk mengukur temperatur lingkungan.

Pemanas listrik digunakan untuk menaikkan temperatur HHX agar terjadi perbedaan temperatur pada kedua sisi stack. HHX dihubungkan dengan glow plug lstrik berdaya maksimal 360 watt dengan tegangan operasi 12 volt arus DC. Battery Charger Transformer (BCT) digunakan sebagai sumber listrik untuk supply arus listrik ke pemanas listrik (glow plug) karena listrik dari PLN mempunyai tegangan 220 volt (arus AC), sementara tegangan maksimal pemanas listrik adalah 12 volt (arus DC).

Kalor yang mengalir dari HHX ke CHX perlu dibuang keluar sistem agar perbedaan temperatur diantara keduanya tetap stabil, sehingga diperlukan sistem pemindah kalor untuk CHX. Pompa akuarium menyuplai air untuk mengitari bagian resonator yang berhimpitan dengan CHX. Air yang masuk dan keluar dikumpulkan dalam ember dengan volume air cukup besar agar kalor yang diserap tidak mengubah temperatur air dalam ember tersebut. Pompa akuarium yang digunakan dengan daya 13 Watt dan debit $700 \mathrm{~L} / \mathrm{h}$.

Bahan yang digunakan dalam penelitian ini adalah wire mesh screen stainless steel. Stack yang dipakai dalam penelitian ini merupakan stack yang terbuat dari laminasi (susunan) wire mesh screen stainless steel. Wire mesh screen dipotong melingkar dengan diameter 2 inchi $(52,5 \mathrm{~mm})$ dan disusun rapat ke dalam resonator dengan ketebalan stack wire mesh screen $30 \mathrm{~mm}$. Stack tersebut diletakkan diantara HHX dan CHX. Pada penelitian ini stack wire mesh screen stainless steel yang digunakan adalah dengan nomor mesh 12 . 


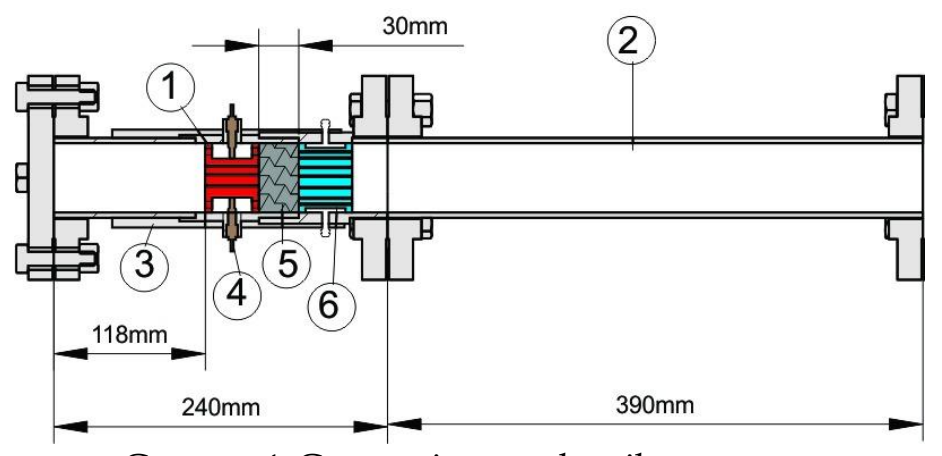

GAMBAR 4. Geometri termoakustik generator

Geometri termoakustik generator yang digunakan dalam penelitian ini tampak pada Gambar 4.

Keterangan Gambar 4. di atas adalah sebagai berikut :

\section{HHX}

2. Resonator

3. Thermal insulation

4. Glow plug

5. Wire mesh

6. $\mathrm{CHX}$

Peralatan yang telah dijelaskan sebelumnya dirakit dengan cara berikut seperti yang terlihat pada Gambar 5:
1. Pemasangan HHX ke dalam housing-nya dengan ikatan ulir. Kemudian pemasangan 6 buah glow plug pada 6 lubang housing sampai menyentuh permukaan HHX.

2. Menghubungkan spool pipa resonator dengan spool pipa CHX dan diberi gasket. Memastikan perapatan yang cukup agar tidak terjadi kebocoran.

3. Stack wire mesh screen disusun rapat di dalam pipa secara acak.

4. Pipa resonator dihubungkan dan diberi gasket pada tiap sambungannya.

5. Termokopel $\left(\mathrm{T}_{1}\right.$ dan $\left.\mathrm{T}_{2}\right)$ dipasang di kedua sisi stack, dan di luar pipa untuk mengetahui temperatur lingkungan.

6. Pompa akuarium diaktifkan untuk mengalirkan air pada temperatur kamar $\left(25^{\circ} \mathrm{C}\right) \mathrm{ke} \mathrm{CHX}$.

7. Alat siap digunakan.

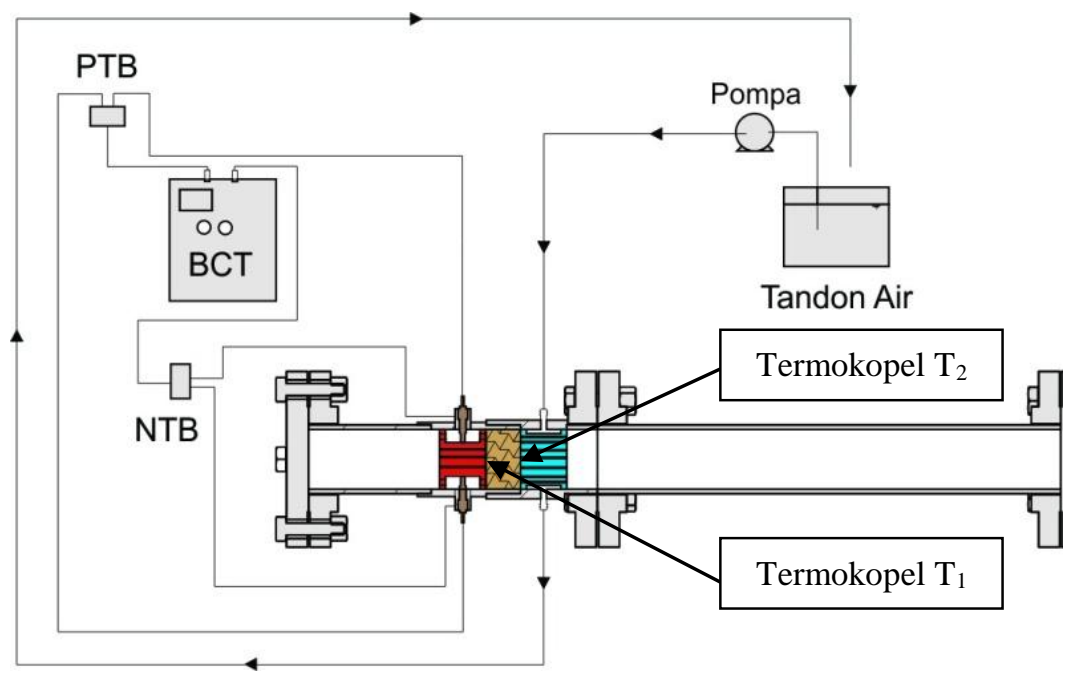

GAMBAR 5. Skema penelitian termoakustik generator 
Alur pengambilan data pada penelitian ini adalah sebagai berikut :

1. Peralatan disiapkan, termasuk stack yang sudah disusun. Eksperimen dilakukan pada tekanan $1 \mathrm{~atm}$ dan temperatur kamar.

2. Ketika semua sudah siap, pemanas listrik diaktifkan dengan mengatur daya input $\approx$ 231 watt.

3. Pencatatan data temperatur yang diukur oleh termokopel tipe-K dicatat dan disimpan dalam format excel. Pencatatan temperatur dilakukan pada sisi stack dekat HHX dan yang lain pada sisi stack dekat CHX seperti yang ditunjukkan pada Gambar 5. Beda temperatur di kedua sisi stack setiap $1^{\circ}$ kenaikan temperaturnya.
4. Pencatatan data temperatur dilakukan hingga gelombang akustik muncul ditandai dengan bunyi yang terdengar dari pipa resonator alat termoakustik generator. Hal ini juga ditandai oleh beda temperatur antara sisi panas dan sisi dingin stack cenderung konstan.

5. Matikan pemanas listrik dan eksperimen berakhir ketika beda temperatur pada kedua sisi stack sama dengan temperatur lingkungan.

6. Langkah (2) sampai (5) dilakukan kembali dengan mengganti sudut kemiringan alat termoakustik generator yang ditunjukkan Gambar 6.

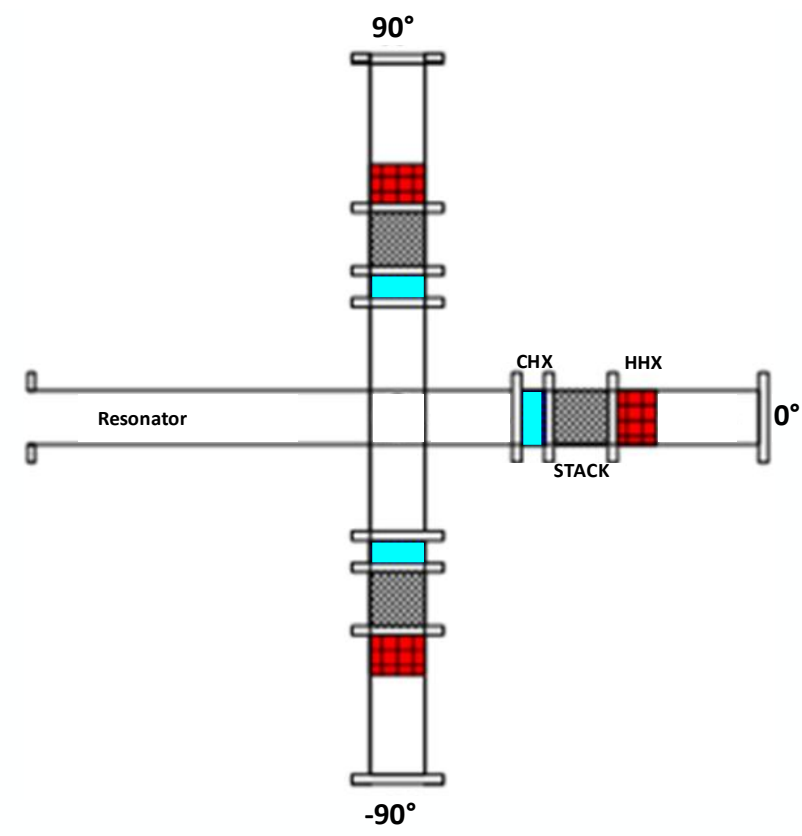

GAMBAR 6. Variasi sudut kemiringan termoakustik generator

\section{HASIL DAN PEMBAHASAN PENELITIAN}

Berikut ini merupakan data temperatur onset yang terjadi pada variasi sudut kemiringan dalam penelitian ini yang ditunjukkan Tabel 2 . Terlihat pada Tabel 2 di atas bahwa sudut kemiringan $-90^{\circ}$ adalah yang terkecil temperatur onsetnya yaitu sebesar $206^{\circ} \mathrm{C}$. Hal ini terjadi karena pada posisi ini inilah arah pada gradien temperaturnya sama dengan arah gravitasinya, maka konveksi natural yang terjadi semakin kuat. Hal ini juga dijelaskan oleh He dkk. (2013) menyatakan bahwa ketika penempatan posisi sudut kemiringannya $-90^{\circ}$, pada kondisi inilah arah pada gradien temperaturnya sama dengan arah gravitasinya, sehingga semakin memperkuat konveksi natural yang terjadi.Sehingga apabila konveksi natural yang terjadi semakin kuat maka distribusi temperatur pada paket gas yang berosilasi diantara HHX ke CHX akan 
semakin baik. Oleh karena itu temperatur onset

yang dicapai akan semakin rendah pula.

TABEL 2. Data temperatur onset berdasarkan perbedaan sudut kemiringan

\begin{tabular}{ccc}
\hline No. & Sudut Kemiringan & Temperatur Onset $\left({ }^{\circ} \mathbf{C}\right)$ \\
\hline 1 & $-90^{\circ}$ & 206 \\
\hline 2 & $0^{\circ}$ & 220 \\
\hline 3 & $90^{\circ}$ & 244 \\
\hline
\end{tabular}

Hal ini dibuktikan juga pada persamaan (1) di atas, jika konveksi natural semakin kuat maka kecepatan osilasi gas kerja u semakin meningkat. Sehingga jika u meningkat maka
$\Delta T_{\text {kritis }}$ akan menurun dan $\Delta T_{\text {onset }}$ ata Temperatur onset juga akan menurun. Telah dijelaskan sebelumnya tentang $\Delta T_{\text {kritis }}$ dan $\Delta T_{\text {onset }}$ pada bab landasan teori di atas.

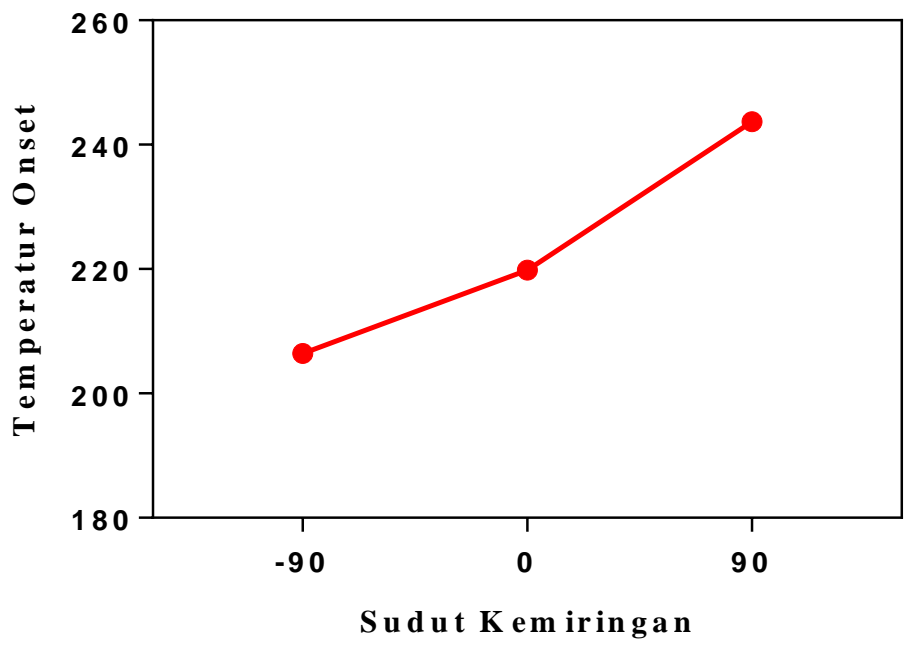

GAMBAR 7. Pengaruh perbedaan sudut kemiringan terhadap temperatur onset termoakustik generator

Gambar 7 menunjukkan tren yang linier yang terjadi pada temperatur onset termoakustik generator berdasarkan perbedaan sudut kemiringannya. Semakin diperbesar sudut kemiringan termoakustik generator maka semakin besar pula temperatur onsetnya, sebaliknya semakin diperkecil sudut kemiringannya semakin kecil temperatur onsetnya. Berdasarkan penjelasan yang sudah dijelaskan sebelumnya, berarti pada sudut kemiringan $-90^{\circ}$ terjadi konveksi natural yang terkuat yang terjadi pada stack-nya, diikuti konveksi natural yang semakin rendah pada sudut kemiringan $0^{\circ}$ dan $90^{\circ}$.

\section{KESIMPULAN}

Berdasarkan hasil dan pembahasan data penelitian disimpulkan bahwa semakin kecil sudut kemiringan maka semakin kecil pula temperatur onset termoakustik generator. Oleh karena itu semakin kecil sudut kemiringan maka semakin kecil energi termal yang dibutuhkan sehingga kinerjanya pada posisi ini adalah yang terbaik jika dilihat dari input energi yang dibutuhkan termoakustik generator. Temperatur onset terkecil terjadi pada sudut kemiringan $-90^{\circ}$ yaitu sebesar $206^{\circ} \mathrm{C}$. Ketika penempatan posisi sudut kemiringannya $-90^{\circ}$, pada kondisi inilah arah pada gradien temperaturnya sama dengan arah gravitasinya, sehingga semakin memperkuat konveksi natural yang terjadi.

\section{UCAPAN TERIMA KASIH}

Penulis mengucapkan terima kasih kepada: 
1. Dr. Adhika Widyaparaga, S.T., M.Biomed.E, selaku kepala laboratorium mekanika fluida Universitas Gadjah Mada yang telah mengijinkan dan menyediakan perlengkapan dan peralatan penelitian untuk penulis.

2. Eddy Saputra Sijabat, S.T., M.Eng., rekan penulis yang telah membantu mempersiapkan alat dalam penelitian yang dipublikasikan dalam jurnal ini.

\section{DAFTAR PUSTAKA}

Arafa N. M., A. H. Ibrahim, K. Addas dan Ehab Abdel-Rahman, 2011, Design considerations for thermoacoustic engines for low onset temperature and efficient operation, Forum Acusticum, Aalborg, Denmark.

Hariharan N.M., Sivashanmugam P., dan Kasthurirengan, 2012, Influence of stack geometry and resonator length on the performance of thermoacoustic engine, 10.1016/j.apacoust.2012.05.003.

Hatazawa M., H. Sugita, T. Ogawa dan Y. Seo, 2004, Performance of a thermoacoustic sound wave generator driven with waste heat of automobile gasoline engine. Trans. Jpn. Soc. Mech. Eng., 70:292-299.

He Y. L., Ke H. B., Cui F. Q., dan Tao W. Q., 2013, Explanation on the onset and damping behaviors in a standing-wave thermoacoustic

engine, 10.1016/j.applthermaleng.2013.0 4.031 .

Murti P., 2015, Studi Eksperimental Pengaruh Jejari Hidrolik dn Panjang Stack Terhadap Kinerja Prime Mover Termoakustik Gelombang Berdiri, Tesis, Jurusan Teknik Mesin dan Industri Universitas Gadjah Mada, Yogyakarta, Indonesia.

Pan N., Wang S., Shen C., 2014, A fundamental study on characteristic of thermoacoustic engine with different tilt angles,

10.1016/j.ijheatmasstransfer.2014.03.01 9.

Setiawan, I., Utomo, A. B. S., Maruto, G, dan Andi, R.W, 2005, Rancang Bangun Piranti Termoakustik Sebagai Pendingin dan Pemanas Secara Simultan, Laporan Penelitian Antar Bidang Ilmu, Proyek
Penelitian Antar Bidang Ilmu, FMIPA UGM, Yogyakarta.

Setiawan I., Masafumi K., dan Makoto N., 2013, Numerical study on the Effect of Working Gases on the Critical Temperature Difference of a Standing Wave Thermoacoustic Prime Mover, Proceeding of The 8th International Conference on Fluid and Thermal Energy Conversion (FTEC 2013), 8-11 November 2013, Semarang, Indonesia.

Shen C., He Y., Li Y., Ke H., Zhang D., dan Liu Y., 2009, Performance of solar powered thermoacoustic engine at different tilted angles,

10.1016/j.applthermaleng.2009.01.008

Zoontjens L., C. Howard, A. Zander dan B. Cazzolate, 2005, Feasibility study of an automotive thermoacoustic refrigerator, Proceedings of acoustics, Busselton, Australia. 